\title{
Preparation and Properties of Porous Polyimide Films Prepared by the Pyrolysis of Poly(urethane-imide) Films
}

\author{
Tsutomu Takeichi, Yutaka Yamazaki, Akihiro Ito, and Min Zuo \\ School of Materials Science, Toyohashi University of Technology, \\ Tempaku-cho, Toyohashi 441-8580, Japan
}

\begin{abstract}
Porous polyimide films were prepared by 2 steps. The first step is the preparation of poly(urethane-imide) films by a reaction between phenol-terminated polyurethane prepolymer and poly(amide acid). Polyurethane prepolymer was prepared from the reaction of polyethylene adipate and hexamethylenediisocyanate. Poly(amide acid) was obtained from pyromellitic dianhydride and oxydianiline. The second step is the pyrolysis of the poly(urethane-imide) films. Upon thermal treatment of the poly(urethane-imide) films at 300 to $400^{\circ} \mathrm{C}$, the thermally less stable urethane domains decomposed, leaving porous polyimide films. The presence of pores was confirmed from the scanning electron microscope of the surface and the cross-section of the films. The size distribution of the pore was narrow. With the increase of urethane content, the size of the pore increased. Tensile measurements revealed that, with the increase of urethane component, tensile modulus did not vary so much, but elongation and thus tensile strength decreased. Viscoelastic analyses showed that all the porous polyimide films had high glass transition temperature at above $400^{\circ} \mathrm{C}$, and storage moduli were maintained up to $400^{\circ} \mathrm{C}$.
\end{abstract}

Keywords: Poly(urethane-imide), Porous polyimide film, Pyrolysis, Pore size

\section{Introduction}

There is a great need for porous materials in industrial applications and in our daily life. Because polyimide is known to have excellent thermal stability and mechanical properties $[1,2]$, porous polyimide is also being interested in many applications such as low dielectrics insulators, gas separation membranes, and light-weight heat insulators, depending on the size of the pore. Porous polyimides are prepared by various method: by using blowing agents [3-6], by the phase inversion of the cast films [7 - 10], and by decomposing thermally labile domain in a phase separated block or graft copolymers [11 - 13].

Recently, we prepared a series of novel poly(urethane-imide) films by a reaction between poly(amide acid) obtained from pyromellitic dianhydride (PMDA) and oxydianiline (ODA) and polyurethane prepolymer obtained from polyethylene adipate and 2,4-tolylene diisocyanate $[14,15]$. Then, we succeeded in preparing a series of porous polyimide films by thermally treating the poly(urethane-imide) films utilizing the phase separation between the thermally stable imide component and thermally labile urethane component [16]. Interestingly, the size of the pore was almost constant irrespective of the urethane content. Instead, the number of pore changed. In this study, we used aliphatic diisocyanate, instead of the aromatic diisocyanate in the previous study, to examine the effect of chemical structure on the pore structure of the porous polyimide films. As a result, we succeeded in controlling the pore size by controlling the ratio of the two components. 


\section{Experimental}

\subsection{Materials}

Pyromellitic dianhydride (PMDA) was purified by recrystallization from acetic anhydride, followed by sublimation. Oxydianiline (ODA) was purified by sublimation. $N$-Methyl-2pyrrolidone (NMP) was purified by distillation under reduced pressure. Hexamethylenediisocyanate (HDI) was used as received. Polyethylene adipate (MW ca. 1000; $\mathrm{OH}$ number in $\mathrm{KOH} ; 113$ ), delivered by Nippon Polyurethane Ltd., was dehydrated in vacuo at $80^{\circ} \mathrm{C}$ for 1 night before use. Phenol was used as received.

2.2. Preparation of poly(amide acid) and polyurethane prepolymer

Poly(amide acid) was prepared from ODA (3 $\mathrm{mmol}, 0.6007 \mathrm{~g}$ ) and PMDA ( $3 \mathrm{mmol}, 0.6544 \mathrm{~g})$ in

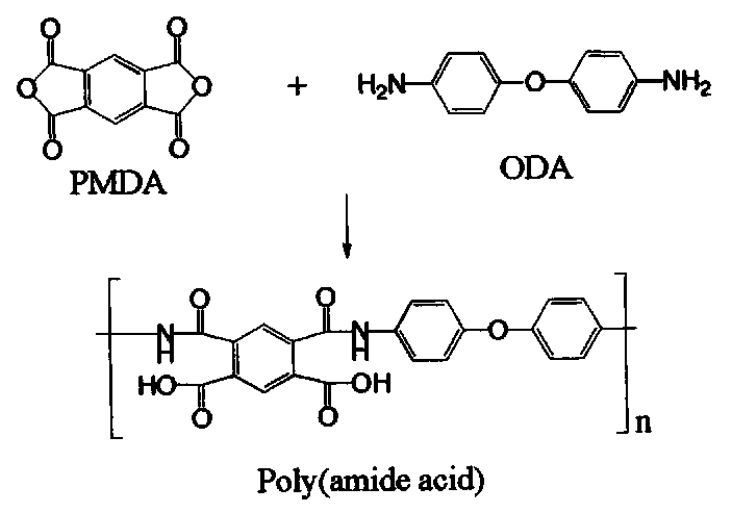

Scheme 1. Preparation of poly (amide acid).

$$
\begin{aligned}
& \left.2 \mathrm{OCN}_{\text {Hexamethylene }}\left(\mathrm{CH}_{2}\right)_{6} \mathrm{NCO}+\mathrm{HO}^{2}\left(\mathrm{CH}_{2}\right)_{2}-\mathrm{O}-\mathrm{O}-\mathrm{C}\left(\mathrm{CH}_{2}\right)_{4}^{\mathrm{O}}-\mathrm{O}\left(\mathrm{CH}_{2}\right)_{2} \mathrm{O}\right]_{n} \\
& \begin{array}{c}
\text { Hexamethylene } \\
\text { diisocyanate }
\end{array} \\
& \downarrow \\
& \mathrm{OCN}\left(\mathrm{CH}_{2}\right)_{6} \mathrm{~N}_{-}^{\mathrm{O}}-\mathrm{C}-\mathrm{Ommmol}_{\text {polyol }} \mathrm{O}-\mathrm{C}-\mathrm{A}\left(\mathrm{CH}_{2}\right)_{6} \mathrm{NCO}
\end{aligned}
$$

Polyurethane prepolymer
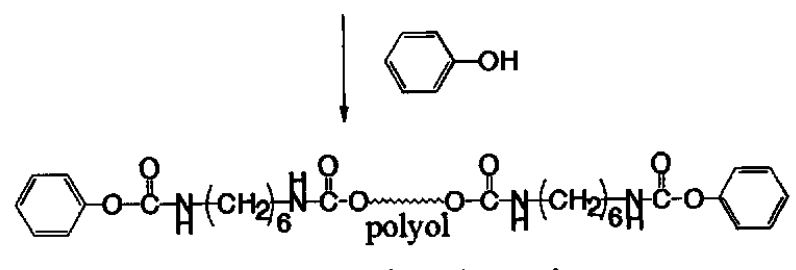

Phenol-terminated prepolymer

Scheme 2. Preparation of polyurethane prepolymer
NMP (11.3 g) under nitrogen atmosphere as shown in Scheme 1 [14]. Viscosities of poly(amide acid) used in this study were in the range of 0.9 $1.5 \mathrm{dL} / \mathrm{g}$ in NMP $(0.5 \mathrm{~g} / \mathrm{dL})$.

Polyurethane prepolymer was prepared, as shown in Scheme 2, by adding HDI $(20.0 \mathrm{mmol}$, $3.36 \mathrm{~g})$ into polyethylene adipate $(10.0 \mathrm{mmol}$, $10.00 \mathrm{~g}$ ) under nitrogen atmosphere and stirred at $80^{\circ} \mathrm{C}$ for $2 \mathrm{~h}$, followed by end capping with $2 \%$ excess of phenol (20.4 mmol, 1.92g) [14].

2.3. Preparation of poly(urethane-imide) films and porous polyimide films

Poly(amide acid) solution in NMP (10 wt \%) and polyurethane prepolymer solution in NMP (50 wt \%) were blended in various ratios at room temperature. The blend solutions were cast on glass plates. After being dried at $50^{\circ} \mathrm{C}$ for $16 \mathrm{~h}$ in vacuo, the films were thermally treated, as fixed on the glass plate, at $100^{\circ} \mathrm{C}$ and $200^{\circ}$ for $1 \mathrm{~h}$ each in vacuo to give poly(urethane-imide) films [14].

The poly(urethane-imide) films were peeled off the glass plate, and then were sandwiched between glass plates that were pre-treated with $5 \%$ of dichlorodimethylsilane in toluene, followed by thermal treatment at 300 and $400^{\circ} \mathrm{C}$ for $1 \mathrm{~h}$ each under ambient pressure to give porous polyimide films.

\subsection{Measurement}

Viscosity of poly(amide acid) was measured using Ubbelohde viscometer at a concentration of $0.5 \mathrm{~g} / \mathrm{dL}$ in NMP. IR spectra were recorded on Jeol Model IR 810. Thermogravimetric analyses (TGA) were carried out with a Seiko I TG/DTA 300 , at a heating rate of $5^{\circ} \mathrm{C} / \mathrm{min}$ under Ar. Dynamic viscoelastic analyses were carried out with a Rheovibron Model DDV-01 FP at a heating rate of $4^{\circ} \mathrm{C} / \mathrm{min}$ in air. Tensile properties were investigated for the films of $2 \mathrm{~cm}$ long using an Imada Seisakusho Model SV-3 at a cross-head speed of $1 \mathrm{~mm} / \mathrm{min}$ at room temperature. Scanning electron micrographs (SEM) were observed with Jeol JSM-6300 or with Hitachi S2300.

\section{Results and Discussion}

3.1. Preparation and properties of poly(urethaneimide) films

Solutions of poly(amide acid) and polyurethane prepolymer in NMP were mixed at various ratios. Cast films were prepared from the clear and transparent solution mixtures. After 
drying at $50^{\circ} \mathrm{C}$, the films became opaque showing phase separation between the two components. The films were converted to poly(urethane-imide) films by treating at $200^{\circ} \mathrm{C}$. The films were still opaque after the heat treatment.

The poly(urethane-imide) films were plastic up to $70 \%$ urethane content. Above $90 \%$ urethane content, poly(urethane-imide) films were sticky and could not be peeled off the glass surface. The tensile properties of the films are summarized in Table 1. With the increase of urethane content, tensile modulus decreased and elongation at break increased.

The viscoelactic properties of the poly(urethane-imide) films were examined. As shown in Fig. 1, lower glass transition temperature based on urethane domain was found at ca $-34^{\circ} \mathrm{C}$, and did not vary irrespective of the urethane content, showing that the urethane and imide components are not miscible.

The poly(urethane-imide) films were examined with thermogravimetric analyses to

Table 1. Tensile properties of poly(urethane-imide) films

\begin{tabular}{rcrc}
\hline $\begin{array}{c}\text { PI/PU } \\
\text { wt \% }\end{array}$ & $\begin{array}{c}\text { Modulus } \\
\text { GPa }\end{array}$ & $\begin{array}{c}\text { Strength } \\
\text { MPa }\end{array}$ & $\begin{array}{c}\text { Elongation } \\
\%\end{array}$ \\
\hline $100 / 0$ & 2.3 & 89 & 31 \\
$90 / 10$ & 2.2 & 120 & 66 \\
$70 / 30$ & 1.8 & 75 & 63 \\
$50 / 50$ & 1.1 & 54 & 66 \\
$30 / 70$ & 0.7 & 28 & 47 \\
\hline
\end{tabular}

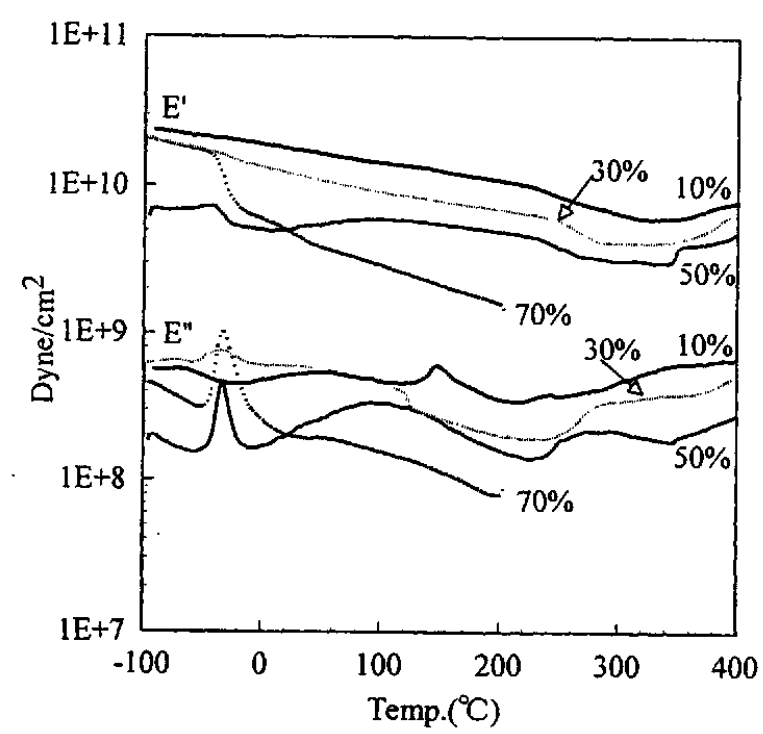

Fig. 1. Viscoelastic analyses of poly(urethane-imide) films of various urethane content. monitor the decomposition process. The decomposition profiles are shown in Fig. 2 for the poly(urethane-imide) films of various polyimide/polyurethane ratios (PI/PU). It was shown clearly that the decomposition occurred in two stages. At a programming rate of $5^{\circ} \mathrm{C} / \mathrm{min}$ of TGA, the first decomposition appeared during the

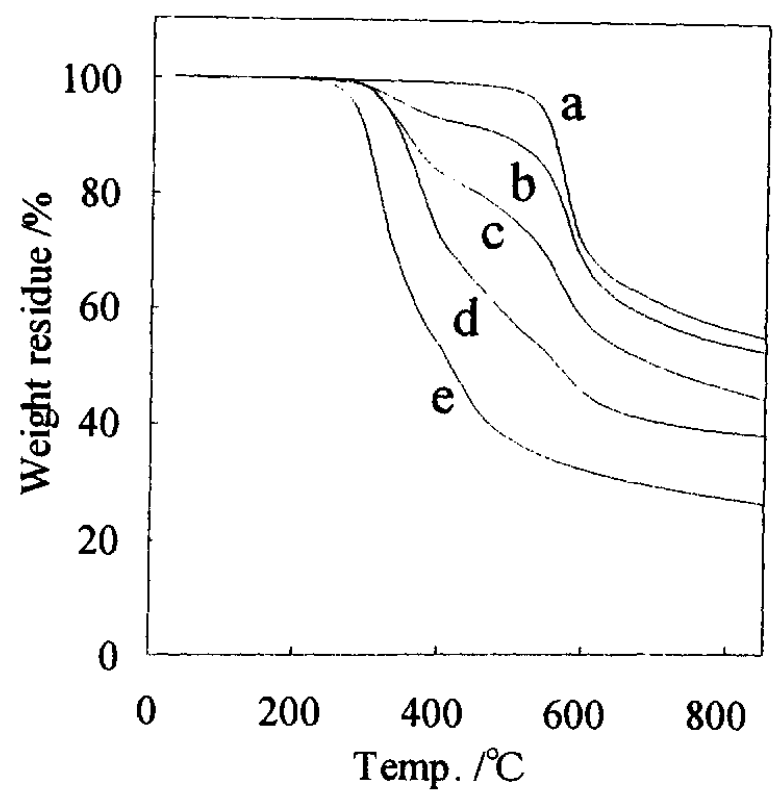

Fig. 2. Thermogravimetric analyses of various poly(urethane-imide). a; polyimide, $b ; P I / P U=90 / 10$, b; PI/PU $=70 / 30$, c; PI/PU $=50 / 50$, d; PI/PU $=30 / 70$

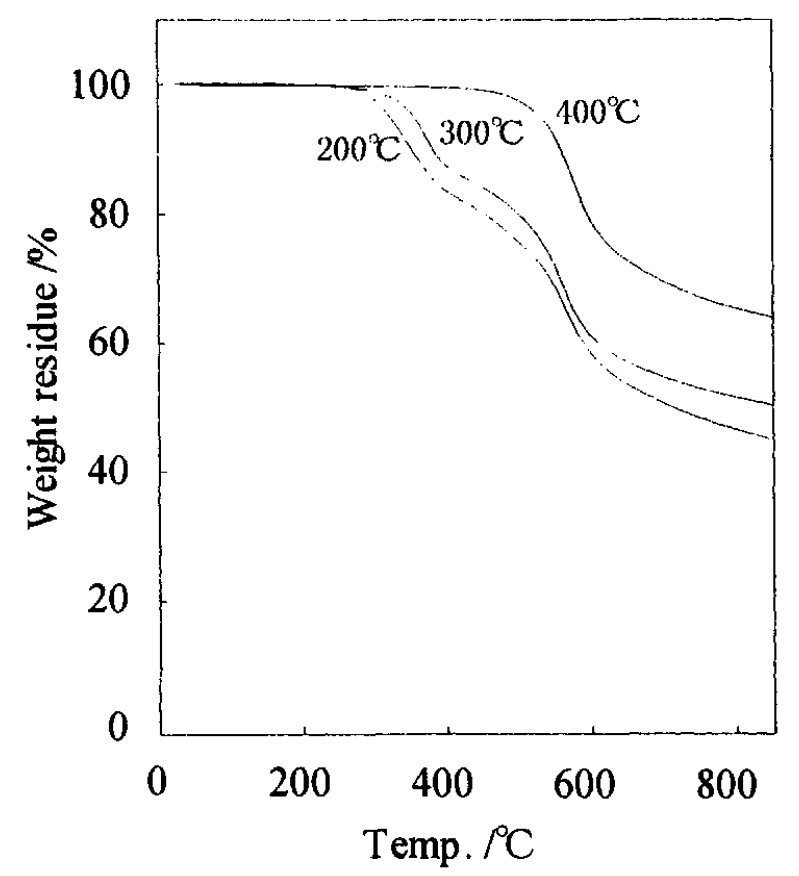

Fig. 3. Thermogravimetric analyses of poly(urethaneimide) films of PI/PU $=70 / 30$ thermally treated at various temperatures. 
a)

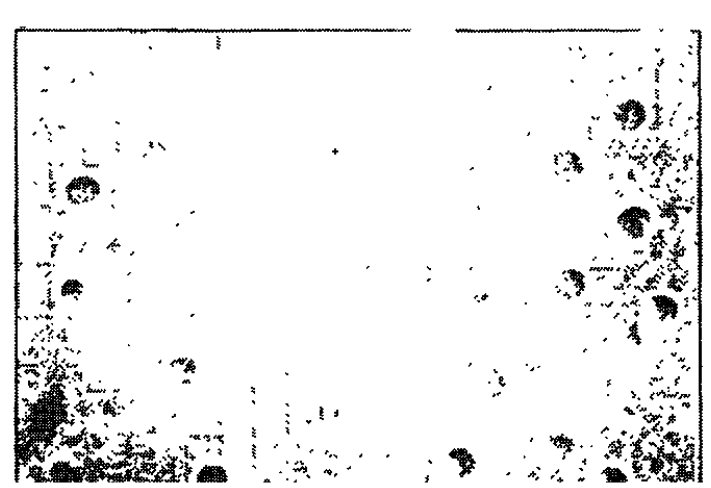

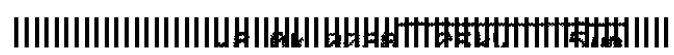

b)

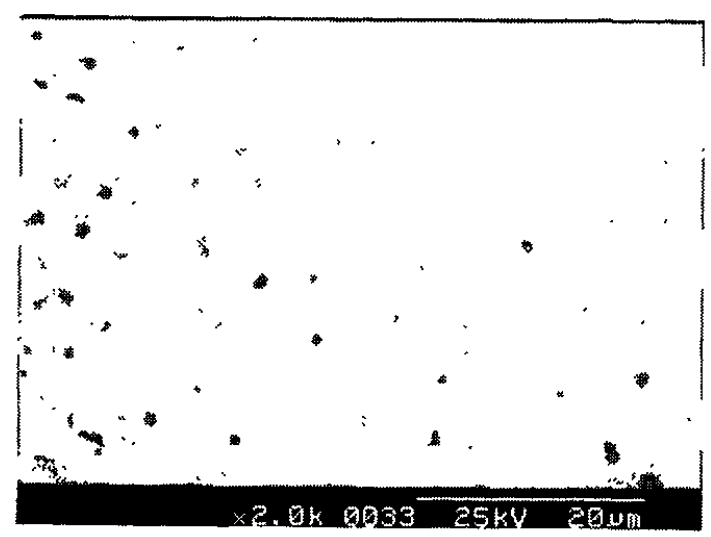

c)

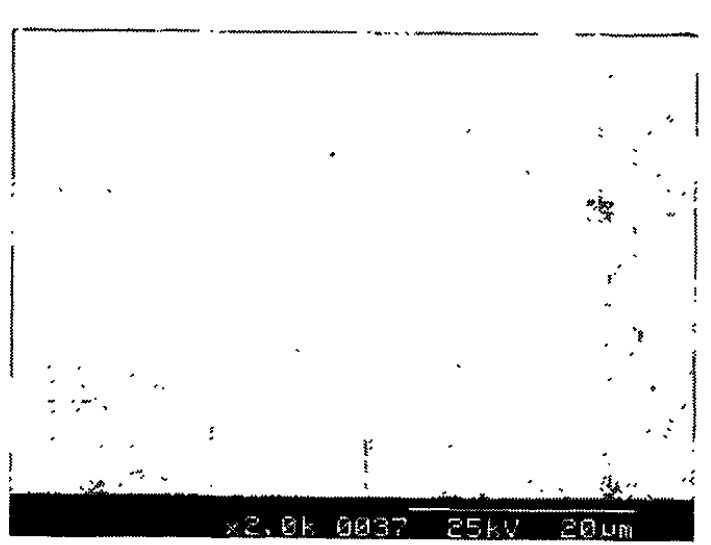

d)

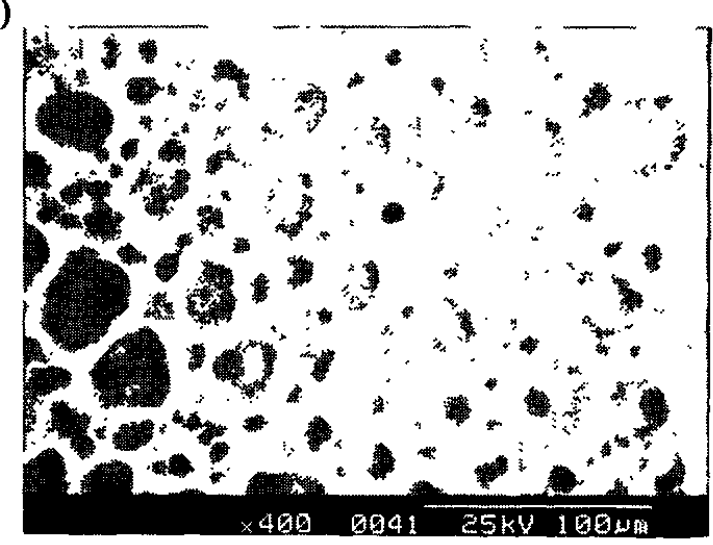

Fig. 4. SEM of the surface of porous polyimide films from various PI/PU. a; PI/PU $=90 / 10$, b) $70 / 30$, c) $50 / 50$, d) $30 / 70$. temperature range of $300^{\circ} \mathrm{C}$ and $400^{\circ} \mathrm{C}$, which is due to the decomposition of the thermally labile urethane component. The second stage occurred above $500^{\circ} \mathrm{C}$, which corresponds to the decomposition of the imide component. Therefore, partial decomposition of the poly(urethane-imide) films at $300-400^{\circ} \mathrm{C}$ could lead to the decomposition of the urethane part only.

\subsection{Preparation of porous polyimide films}

Thus, poly(urethane-imide) films were thermally treated at 300 and $400^{\circ} \mathrm{C}$ for $1 \mathrm{~h}$ each to decompose urethane component and to obtain porous polyimide films. The films became brown-colored but transparent for those with low urethane content (PI/PU 90/10 and 80/20). The films became dark brown and opaque for those with higher urethane content (PI/PU less than 70/30). This is supposed to come from the formation of char originating from urethane component. From the TGA of the films thermally treated at various temperatures (Fig. 3), it was shown that the films have to be treated at $400^{\circ} \mathrm{C}$ to completely decompose the urethane domains. It was also shown from Fig. 3 that porous polyimide films treated at $400^{\circ} \mathrm{C}$ is as thermally stable as the standard PMDA/ODA films.

\subsection{Pore structure of porous polyimide films}

The surface of the films treated at $400^{\circ} \mathrm{C}$ looked smooth, but SEM of the films clearly showed the presence of pores. Examples of SEM are shown in Fig. 4, and the size distribution of pores counted from the SEM photographs are shown in Fig. 5.

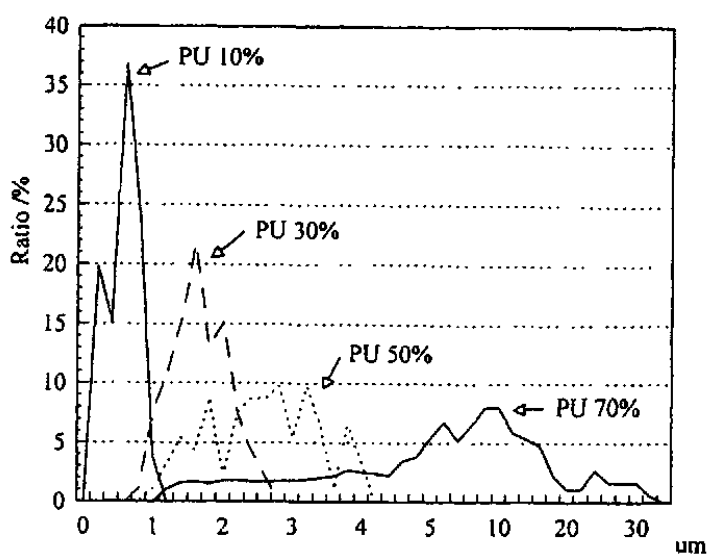

Fig. 5. Pore size distribution of porous polyimide films with various urethane content. 
Table 2. Average pore size of porous polyimide films

\begin{tabular}{ccc}
\hline $\begin{array}{c}\text { PI/PU } \\
\text { wt \% }\end{array}$ & $\begin{array}{c}\text { Treatment } \\
{ }^{\circ} \mathrm{C}\end{array}$ & $\begin{array}{c}\text { Pore size } \\
\mu \mathrm{m}\end{array}$ \\
\hline $90 / 10$ & 300 & 0.7 \\
& 400 & 0.9 \\
$70 / 30$ & 300 & 1.9 \\
& 400 & 2.2 \\
$50 / 50$ & 300 & 3.2 \\
& 400 & 3.9 \\
$30 / 70$ & 300 & 21.2 \\
& 400 & 30.1 \\
\hline
\end{tabular}

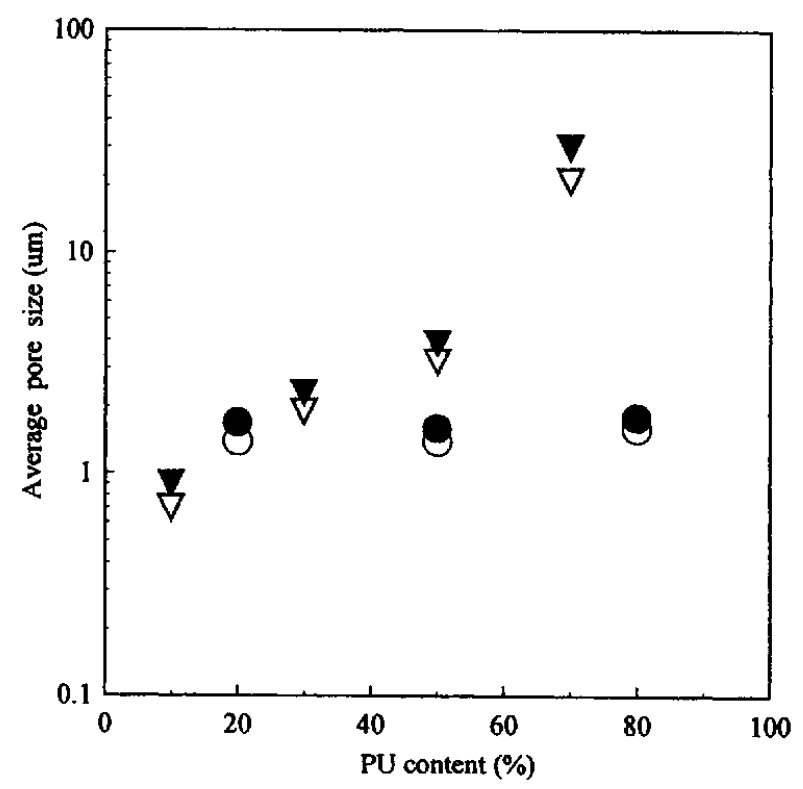

Fig. 6 Average pore size of porous polyimide films. $\mathrm{O}$; TDI, $300^{\circ} \mathrm{C}, \mathrm{TDI}, 400^{\circ} \mathrm{C}, \nabla ; \mathrm{HDI}, 300^{\circ} \mathrm{C}, \nabla$; HDI, $400^{\circ} \mathrm{C}$.

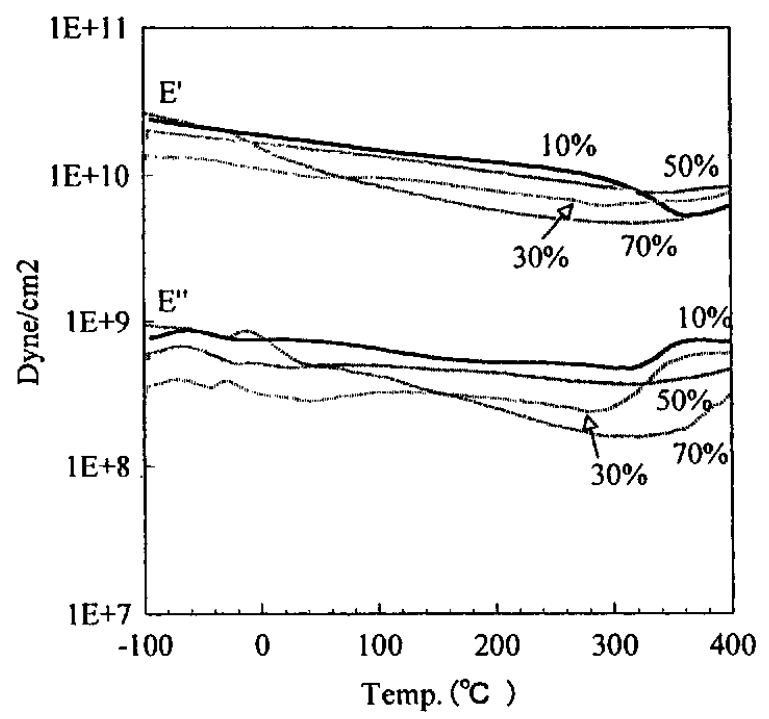

Fig. 7. Viscoelastic analysis of porous polyimide films treated at $300^{\circ} \mathrm{C}$
The size of the pores looks rather homogeneous and the size distribution is narrow. It was found that the pore size increased with the increase of the urethane content and also with the increase of decomposition temperatures (Table 2). The large shift of pore size in this study using HDI is strikingly different from the previous study using TDI that pore size did not vary and number of pore varied (Fig. 6).

\subsection{Physical Properties of porous polyimide films}

Tensile properties of the porous polyimide films are summarized in Table 3. It can be seen that films from higher urethane content show shorter elongation at break and thus are more brittle; from $61 \%$ to $2.2 \%$ for the $300^{\circ} \mathrm{C}$ treated films, and $17 \%$ to $0.7 \%$ for the $400^{\circ} \mathrm{C}$ treated films.

Table 3. Tensile properties of porous polyimide films

\begin{tabular}{ccccc}
\hline $\begin{array}{c}\text { PI/PU } \\
\text { wt \% }\end{array}$ & $\begin{array}{c}\text { Treatment } \\
{ }^{\circ} \mathrm{C}\end{array}$ & $\begin{array}{c}\text { Modulus } \\
\text { GPa }\end{array}$ & $\begin{array}{c}\text { Strength } \\
\text { MPa }\end{array}$ & $\begin{array}{c}\text { Elongation } \\
\%\end{array}$ \\
\hline $100 / 0$ & 300 & 2.0 & 91 & 32 \\
& 400 & 2.4 & 109 & 17 \\
$90 / 10$ & 300 & 2.3 & 107 & 61 \\
& 400 & 2.7 & 102 & 11 \\
$70 / 30$ & 300 & 2.1 & 73 & 15 \\
& 400 & 2.7 & 48 & 2.1 \\
$50 / 50$ & 300 & 1.9 & 53 & 6.6 \\
& 400 & 2.6 & 19 & 0.7 \\
$30 / 70$ & 300 & 1.7 & 37 & 2.2 \\
& 400 & - & - & - \\
\hline
\end{tabular}

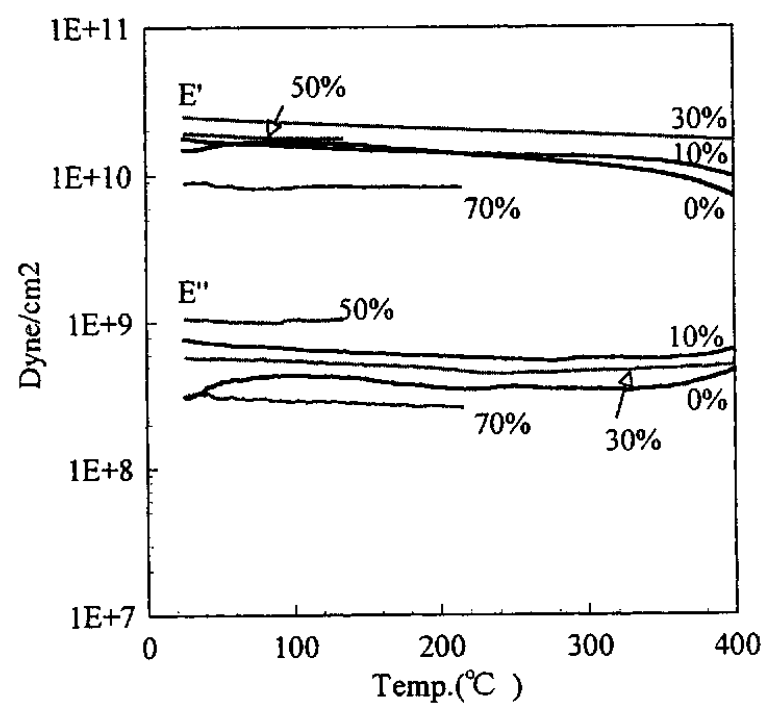

Fig. 8. Viscoelastic analysis of porous polyimide films treated at $400^{\circ} \mathrm{C}$ 
Tensile strength also decreased with films from high urethane content. Higher heat treatment also gave lower elongation and more brittle films due to the increased pore formation. Tensile moduli of the films, however, did not decrease so much with the increase of pore volume. They were in the range of c.a. $1.7-2.7 \mathrm{GPa}$.

Viscoelastic analyses of porous polyimide films treated at $300^{\circ} \mathrm{C}$ and $400^{\circ} \mathrm{C}$ are shown in Figs. 7 and 8, respectively. Lower $\mathrm{Tg}$ was observed in the porous polyimide films pyrolyzed at $300^{\circ} \mathrm{C}$, indicating the imcomplete pyrolysis of the urethane component. Lower $\mathrm{Tg}$ was not observed after $400^{\circ} \mathrm{C}$ treatment. Though the porous polyimide films from high urethane content were brittle after $400^{\circ} \mathrm{C}$ treatment, Tg's of all the films were as high as above $400^{\circ} \mathrm{C}$, and storage moduli were maintained up to high temperatures. The high temperature properties of the porous polyimide films were almost the same as the Kapton-type polyimide films, and were not affected in spite of the presence of pore.

\section{Conclusion}

Porous polyimide films were obtained by thermal treatment of the poly(urethane-imide) films at $300-400^{\circ} \mathrm{C}$. The size of the pores depended on the ratio of the two components. The increase of polyurethane content tends to give brittle films with higher pore volume. The porous polyimide films maintained the excellent thermal properties of the nonporous conventional polyimide films such as high glass transition temperature, thermal stability, and excellent mechanical properties at high temperatures.

\section{Acknowledgment}

This work was partially supported by the Ministry of Education, Science, Sports and
Culture, Grant-in-Aid for Scientific Research on Priority Areas (Carbon Alloys), 10137228, 1998.

\section{References}

1. Polyimides: Fundamentals and Applications, M. K. Ghosh and K. L. Mittal, Ed., Marcel Dekker, Inc., New York (1996).

2. Polyimides: Trends in Materials and Applications, C. Feger, M. M. Khojasteh and S. E. Molis, Ed., Society of Plastics Engineerings, Mid Hudson Section (1996).

3. C. M. Krutchen and W.-P. Wu, US Patent, No. 4 535100 (1985); C. M. Krutchen and W.-P. Wu, US Patent, No. 4532263 (1985).

4. R. W. Smearing and D. E. Floryan, US Patent, No. 4543368 (1985).

5. W. J. Farrissey, Jr., J. S. Rose and P. S. Carleton, J. Appl. Polym. Sci., 14 (1970) 1093.

6. J. Gagliani and D. E. Sepkis, Adv. Astronaut. Sci., 38 (1979) 193.

7. H. Yanagishita, D. Kitamoto and T. Nakane, High Performance Polymers, 7 (1995) 275.

8. H. Kawakami and S. Nagaoka, ASAIO J., 41 (1995) M379.

9. Y. Echigo, Y. Iwaya, M. Saito and I. Tomioka, Macromolecules, 28 (1995) 6684.

10. H. Hatori, Y. Yamada and M. Shiraishi, J. Appl. Polym. Sci., 57 (1995) 871.

11. Y. Charlier, J. L. Hedrick, T. P. Russell, A. Jonas and W. Volksen, Polymer, 36 (1995) 987.

12. J. L. Hedrick, R. Dipietro, C. J. G. Plummer, J. Hilborn and R. Jerome, Polymer, 37 (1996) 5229.

13. K. R. Carter, R. Richter, H. R. Kricheldorf and J. L. Hedrick, Macromolecules, 30 (1997) 6074.

14. M. Zuo and T. Takeichi, J. Polym. Sci.: Part A: Polym. Chem., 35 (1997) 3745.

15. M. Zuo, Q. Xian and T. Takeichi, Polymer, 39 (1998) 6883.

16. T. Takeichi, M. Zuo and A. Ito, High Performance Polym., in press. 